jkcvhl.com

KIDNEY CANCER: ORIGINAL ARTICLE

\title{
Von Hippel-Lindau Syndrome: Medical Syndrome or Surgical Syndrome? A Surgical Perspective
}

\section{Danilo Coco ${ }^{1}$, Silvana Leanza²}

${ }^{1}$ Department of General Surgery, Ospedali Riuniti Marche Nord, Pesaro, Italy; ${ }^{2}$ Department of General Surgery, Carlo Urbani Hospital, Jesi, Italy

\begin{abstract}
Von Hippel-Lindau syndrome (VHL) is an autosomal dominant disease caused by a genetic aberration of the tumor suppressor gene VHL and characterized by multi-organ tumors. The most common neoplasm is retinal or cerebral hemangioblastoma, although spinal hemangioblastomas, Renal Clear Cell Carcinoma (RCCC), pheochromocytomas (Pheo), paragangliomas, Pancreatic Neuroendocrine Tumors (PNETs), cystadenomas of the epididymis, and tumors of the lymphatic sac can also be found. Neurological complications from retinal or CNS hemangioblastoma and metastases of RCCC are the most common causes of death. There is a strong association between pheochromocytoma and VHL syndrome, and pheochromocytoma is often a classic manifestation of the syndrome. RCCCs are often incidental and identified during other tests. Between 35 and $70 \%$ of patients with VHL have pancreatic cysts. These can manifest as simple cysts, serous cysto-adenomas, or PNETs with a risk of malignant degeneration or metastasis of no more than $8 \%$. The objective of this retrospective study is to analyze abdominal manifestations of VHL from a surgical point of view.
\end{abstract}

Keywords: clear cell renal cancer; Pheocromocytoma; PNET; Von Hippel-Lindau

Received: 19 September 2021; Accepted after revision: 24 October 2021; Published: 5 December 2021

Author for correspondence: Danilo Coco, MD, Department of General Surgery, Ospedali Riuniti Marche Nord, Pesaro, Italy. Email: webcostruction@msn.com

How to cite: Coco D and Leanza S. Von Hippel-Lindau Syndrome: Medical Syndrome or Surgical Syndrome?A Surgical Perspective. J Kidney Cancer VHL. 2022; 9(1): 27-32.

Doi: https://doi.org/10.15586/jkcvhl.v9i1.206

Copyright: Coco D

License: This open access article is licensed under Creative Commons Attribution 4.0 International (CC BY 4.0). http://creativecommons.org/ licenses/by/4.0

\section{Introduction}

In 1894, Collins reported a bilateral incidence of retinal hemangioblastomas in twins, which were referred to as nevi, whereas the German ophthalmologist Von Hippel discussed cases of retinal angiomatosis. In 1926, the Sweden pathologist Lindau identified an association between the retinal angiomatosis and the hemangioblastomas in the cerebellum. In the 1960s, the disease was termed Von Hippel-Lindau disease (VHL) (1-3). From 1960 to 1990, VHL disease was diagnosed on the basis of clinical signs and symptoms. However, in 1988, Seizinger et al. (4) identified an alteration on the short arm of chromosome 3 (3p25-3p26). In 1993, it became possible to isolate the gene responsible for the disease, which was named the VHL gene $(4,5)$. VHL is an autosomal dominant disease caused by genetic aberration of the tumor suppressor gene. It is characterized by multi-organ tumors 
of the central nervous system, kidney, pancreas, and adrenal and reproductive organs. The most common neoplasm is retinalor cerebral hemangioblastoma, although spinal hemangioblastomas, Renal Clear Cell Carcinoma (RCCC), pheochromocytomas (Pheo), paragangliomas, Pancreatic Neuroendocrine Tumors (PNETs), cystadenomas of the epididymis, and tumors of the lymphatic sac can also be found. Life expectancy is approximately 60 years for men and 50 years for women. VHL related mortality is due to complications from CNS and RCCC tumors (6-8). The onset of symptoms appear in the second decade of life; it therefore develops in childhood or adolescence. It has an incidence rate of 3:100,000 people per year. The VHL gene is located on chromosome $3 \mathrm{p} 25$, which consists of three exons for the pVHL gene (a tumor suppressor protein). When the pVHL is not produced due to mutations in the VHL gene (mainly deletions), angiogenesis and uncontrolled cell proliferation are promoted. Therefore, the pVHL mutations seriously increase the risk of tumor growth in the organs indicated (8-10). Approximately $70 \%$ of the VHL cases are hemangioblastomas and clear renal cell carcinoma (RCC). The latter is often the main factor affecting prognosis, with kidney cancer being the most common cause of death. For these patients, there is an association between VHL and (i) PNETs with an incidence ranging from 5 to $18 \%$ and (ii) (Pheo) that occur in up to $20 \%$ of the patients $(11-15)$. The objective of this retrospective study is to analyze abdominal manifestations of VHL from a surgical point of view.

\section{Materials and Methods}

We conducted a retrospective evaluation of PubMed articles. A total of 6537 results appeared when searching for VHL. The pool of results were then massively reduced by only selecting articles from 2000 to 2021. A combination of medical subject heading $(\mathrm{MeSH})$ terms and keywords were used for the search. The inclusion criteria were "Von Hippel-Lindau; Pheocromocytoma; Clear Cell Renal Cancer; PNET." The primary outcome measure was "VHL surgical treatment." Two authors analyzed the articles. The methodologies applied in the articles were randomized controlled trials (RCTs), cohort studies, case-control studies, randomized studies, and prospective and retrospective studies. Studies in all languages were included. We excluded case reports and articles not focused on surgical management.

\section{Results}

In a retrospective study, Zwolak et al. (16) found that in the general population, PNETs in VHL have an estimated incidence of approximately 5-18\%. However, PNETs comprise only $5 \%$ of pancreatic cancers and the association between PNETs and VHL is less than $0.5 \%$. Distant metastases are found in $60-90 \%$ of sporadic PNETs, whereas in VHL the incidence of metastases is estimated at $11-20 \%$. Sporadic non-secreting neuroendocrine tumors of the pancreas should be removed when they are greater than $20 \mathrm{~mm}$ in diameter. Smaller tumors can be observed if they do not exhibit radiological or histopathological features of malignancy. Hes et al. (17) conducted a genetic analysis of VHL, targeting the formation of pheochromocytomas. They highlighted 3 types of VHL associated with 3 subtypes classification: Type 1, not from pheochromocytomas and mutations in patients with this type of VHL; Type 2, which has the appearance of pheochromocytomas and can be further subdivided into 3 subtypes: low (type 2A), and high (type 2B) risk of RCC, type $2 \mathrm{C}$ families with pheochromocytoma only, type $3 \mathrm{Chu}-$ vash polycythemia.. In an extensive review of the relevant literature, Varshney et al. (18) found multiple bilateral renal cysts in $50-70 \%$ of patients with VHL, and RCC in $30 \%$ of patients with VHL. In the third or fourth decade of life, renal cysts are often multiple but asymptomatic and without renal insufficiency or with RCC. They noted that RCC, which is the main cause of mortality in this group of patients, has an incidence of $70 \%$ after the age of 60 . Pheochromocytomas occur in up to $20 \%$ of VHL patients in the second decade of life; these are bilateral or multifocal and secrete catecholamines. The treatment of choice for pheochromocytomas is surgical resection using laparoscopic approaches. Approximately $35-70 \%$ of the patients with VHL have pancreatic cysts. Baghai et al. (19), in their retrospective study at Mayo Clinic Hospital, analyzed 109 patients affected by VHL. They found $46 \%$ of RCCC, $76 \%$ of cerebral or cerebellar hemangioblastoma, $63 \%$ of retinal angioma, $16 \%$ of pheocromocytoma, $3 \%$ of paraganglioma, and $43 \%$ of pancreatic lesions. After open or laparoscopic adrenalectomy for Pheo, mean size was between 1.5 and $6.5 \mathrm{~cm}$ with no invasive tumors or metastases (16 patients), and $50 \%$ of these had concurrent procedure for pancreatic cancer or renal cancer (Table 1).

\section{Discussion}

VHL disease is an autosomal, dominant hereditary tumor syndrome with an estimated prevalence of 2-3 per 100,000 people. It predisposes people to hemangioblastoma in the retina, cerebellum, and spine; renal cell carcinoma, pheochromocytoma; islet cell tumors of the pancreas; endolymphatic sac tumors; and cysts in the pancreas and epididymis. Neurological complications from retinal or CNS hemangioblastoma and metastases of RCC are the most common causes of death $(5,8,20)$. The current clinical classification of VHL comprises three types, 1-2-3. Of these, type 2 contains three subtypes. Type 1 is characterized by a high risk of renal cell carcinoma. Types $2 \mathrm{a}$ and $2 \mathrm{~b}$ are characterized by a high risk of both renal cell carcinoma and pheochromocytoma, whereas type $2 \mathrm{c}$ is characterized by a high risk of pheochromocytoma. 


\begin{tabular}{|c|c|c|c|c|}
\hline ङ & 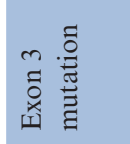 & 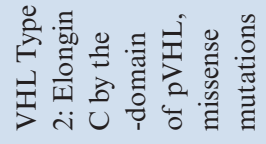 & । & $\overleftrightarrow{\mathrm{z}}$ \\
\hline  & & 尾芳 & 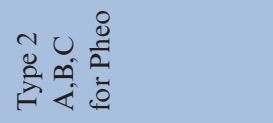 & $\overleftrightarrow{z}$ \\
\hline$\stackrel{\frac{\emptyset}{0}}{0}$ & $\overleftrightarrow{\mathrm{z}}$ & & 1 & 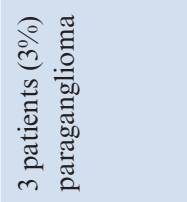 \\
\hline 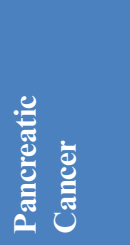 &  & & 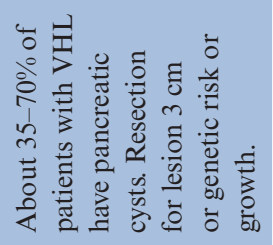 & 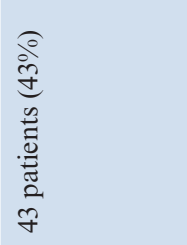 \\
\hline ల & $\overleftrightarrow{\mathrm{Z}}$ & & 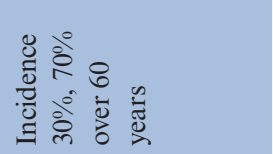 & 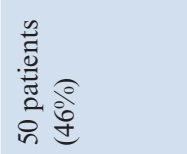 \\
\hline 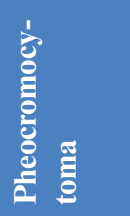 & $\overleftrightarrow{Z}$ & $\frac{8}{2}$ &  & 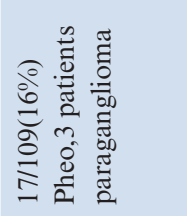 \\
\hline 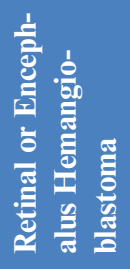 & $\overleftrightarrow{\mathrm{z}}$ & & 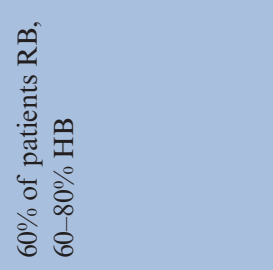 & 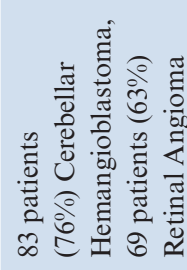 \\
\hline 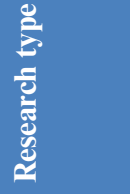 & 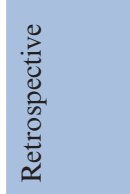 &  & 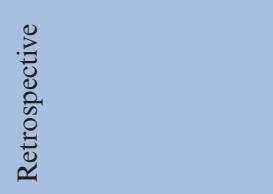 & 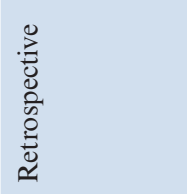 \\
\hline 离言竞 & & $\overleftrightarrow{z}$ & $\overleftrightarrow{\measuredangle}$ & 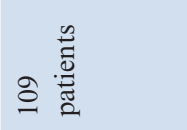 \\
\hline 章 & 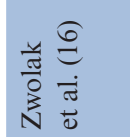 & 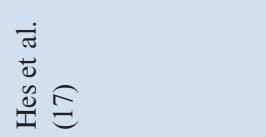 & 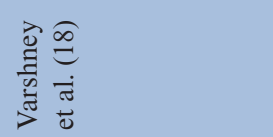 & 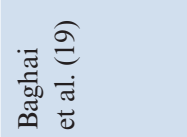 \\
\hline
\end{tabular}


Type 3 is characterized by a risk of Chuvash polycythemia (8-10) (Table 2). Currently, there are no guidelines for the management of hemangioblastoma. Patients with hemangioblastoma inoperable for local dimensions or who are not fit because they are at a high risk of operative complications can be managed with conventional fractional radiotherapy or stereotaxic radiosurgery. Small hemangioblastomas appear to benefit from conservative treatment with radiological follow-up. Therefore, only symptomatic hemangioblastomas should be managed operatively (Weil). Preoperative embolization of hemangioblastomas also appears to be acceptable and safe; this procedure reduces blood loss during surgery and the incidence of postoperative complications (21). There is a strong association between pheochromocytoma and VHL syndrome, and pheochromocytoma is often a classic manifestation of the latter. Pheochromocytoma occurs in up to $20 \%$ of patients with VHL in the second decade of life and can be bilateral or multifocal. It typically develops in young adults and its location may be adrenal or extra-adrenal. Often, they may exhibit a low secretory activity while classic symptoms (such as tachycardia, sweating, tachypnea, headache, angina, and palpitations) may be absent. The treatment of choice for pheochromocytomas is surgical resection using either a laparoscopic transperitoneal, extraperitoneal, or robotic laparoscopic approach $(22,23)$. This approach yields excellent results with no recurrence $(24,25)$. RCCs are often incidental and identified during other tests. Partial nephrectomy is recommended for $3 \mathrm{~cm}$ tumors. Nephro-sparing on lesions of $3 \mathrm{~cm}$ or greater result in 10 year cancer survival rates of up to $81 \%$. Percutaneous and laparoscopic radiofrequency ablation therapy is effective in the treatment of smaller tumors $(<3 \mathrm{~cm})(26,27)$. The pancreatic lesions found in VHL disease are a heterogeneous group comprising the following: PNETs, simple cysts, serous cystadenomas, and mixed neuroendocrine neoplasms. Cysts are the most common and have been found in $17-72 \%$ of the cases $(28-30)$.
Pancreatic resection is performed only for PNETs measuring at least $2 \mathrm{~cm}$ in size or any size if they have malignant characteristics. Small tumors can be observed if no radiological or histopathological features of malignancy are exhibited. If a pancreatic NET is small, enucleation is performed. A distal pancreatectomy is used to treat PNETs present in the tail and body of the pancreas. Surgical options involve removing only the tail of the pancreas or performing a pancreatic splenectomy via open surgery or laparoscopy or robotics. A Whipple procedure is used to treat pancreatic NETs found in the head of the pancreas. A central pancreatectomy is used to treat small, low grade tumors $(31,32)$. Blansfield et al. (13) identified three main factors that can determine the risk of metastasis: tumor size, exon 3 mutation, and mean doubling time. There is an apparent $12 \%$ association between neuroendocrine tumors of the pancreas and pheochromocytomas in patients with VHL disease (33). Approximately 35-70\% of patients with VHL have pancreatic cysts. These can manifest as simple cysts, serous cysto-adenomas, or PNETs with a risk of malignant degeneration or metastasis of no more than $8 \%$. The resection criteria are given by a major tumor of $3 \mathrm{~cm}$ or a pathogenic variant in exon 3 and tumor with a growth rate doubling in fewer than 500 days. Because these characteristics increase the risk of metastasis, enucleation, Whipple, or distal pancreatectomy is indicated depending on the site $(13,34$, 35). In recent years new medical therapies targeting the VHL/ HIF axis have been investigated, with some of them being used in clinical trials. The most commonly utilized are tyrosine kinase inhibitors (TKIs), which can decrease angiogenesis by blocking the VEGF pathway. Several TKIs including sunitinib, cabozantinib, axitinib, lenvatinib, and pazopanib are currently being evaluated in phase II clinical trials. These therapies work by inhibiting cancer cell proliferation, metastasis, and the development of therapeutic resistance by suppressing tyrosine kinase receptors (36). Recently, studies were investigated on belzutifan, development code: MK-6482,

Table 2: Type of VHL, clinical findings, gene mutations, and notes.

\begin{tabular}{|l|l|l|l|}
\hline Type of VHL & Clinical findings & Gene & Notes \\
\hline Type 1 & $\begin{array}{l}\text { Retinal and CNS HB, RCCC, pancreaticcysts, and } \\
\text { neuroendocrine tumors }\end{array}$ & $\begin{array}{l}\text { Missense } \\
\text { mutations }\end{array}$ & Decreased risk for Pheo \\
\hline Type 2 & & Missense mutation & Low risk for RCC \\
\hline Type 2A & CNS and retinal HB Pheo & - & High risk of RCC \\
\hline Type 2B & $\begin{array}{l}\text { RCCC, Retinal HB, CNS HB,pancreatic cyst, and } \\
\text { neuroendocrinetumors, Pheo }\end{array}$ & - & High risk of Pheo \\
\hline Type 2C & Pheo & - & - \\
\hline Type 3 & Chuvash polycythemia. & \\
\hline
\end{tabular}

CNS: central nervous system; HB: hemangioblastoma; RCCC: Renal Clear Cell Carcinoma; Pheo: Pheocromocytoma. 
which is a hypoxia-inducible factor-2 $\alpha$ (HIF-2 $\alpha$ ) inhibitor for the treatment of adult patients with Hippel-Lindau syndrome. This agent is not FDA approved in US and had a $83 \%$ response rate in PNETs (37-39).

\section{Conclusions}

VHL syndrome exhibits a wide range of signs and symptoms and is often difficult to diagnose. It is a multisystem tumor syndrome with common manifestations affecting the CNS and various visceral organs. VHL patients often require multidisciplinary treatment, including genetic counseling and personnel such as surgeons, radiologists, pathologists, and oncologists. Early identification of mutations leads to early intervention and reduces rates of morbidity and mortality. Although the use of surgery to treat hemangioblastomas yields promising results, RCC appears to benefit considerably from a combination of surgery and the use of targeted therapies such as VEGF. The future promises an even greater understanding of the genetic structure of the disease, facilitating its treatment with increasingly specific drugs.

\section{Declaration of Interest}

Nothing to declare for all authors.

\section{Funding}

No funding.

\section{Author's Contribution}

Danilo Coco conceptualized, searched the literature, and wrote first draft; Silvana Leanza constructed the tables, analyzed the data, and revised the first draft; Danilo Coco and Silvana Leanza edited the final draft. All authors agreed to submit the article for publication.

\section{Author Contributions}

Danilo Coco MD and Silvana Leanza MD contributed to this paper; Danilo Coco designed the overall concept and outline of the manuscript; Silvana Leanza contributed to the discussion and design of the manuscript; Danilo Coco MD and Silvana Leanza MD contributed to the writing, and editing the manuscript, illustrations, and review of literature.

Supported by Danilo Coco MD and Silvana Leanza MD.

\section{References}

1. Collins E. Intra-ocular growths (two cases, brother and sister, with peculiar vascular new growth, probably retinal, affecting both eyes).Trans Ophthalmol Soc U K. 1894;14:141-9.
2. von Hippel E. U“ ber eine sehr seltene Erkrankung der Netzhaut. Gra"fe Arch Ophthallmol. 1904;59:83-106. https:// doi.org/10.1007/BF01994821

3. Lindau A. Zur Frage der Angiomatosis retinae und ihrer Hirnkomplikation. Acta Ophthalmol. 1927;4:193-224. https:// doi.org/10.1111/j.1755-3768.1926.tb07786.x

4. Seizinger BR, Rouleau GA, Ozelius LJ, et al. Von HippelLindau disease maps to the region of chromosome 3 associated with renal cell carcinoma. Nature. 1988;332:268-9. https://doi. org $/ 10.1038 / 332268 \mathrm{a} 0$

5. Latif F, Tory K, Gnarra J, Yao M, Duh FM, Orcutt ML, Stackhouse T, Kuzmin I, Modi W, Geil L, et al. Identification of the von Hippel-Lindau disease tumor suppressor gene. Science. 1993 May 28;260(5112):1317-20. http://dx.doi.org/10.1126/ science.8493574. PMID: 8493574.

6. Wilding A, Ingham SL, Lalloo F, Clancy T, Huson SM, Moran A, Evans DG. Life expectancy in hereditary cancer predisposing diseases: an observational study. J Med Genet. 2012 Apr;49(4):264-9. http://dx.doi.org/10.1136/ jmedgenet-2011-100562. Epub 2012 Feb 23. PMID: 22362873.

7. Poulsen ML, Budtz-Jørgensen E, Bisgaard ML. Surveillance in von Hippel-Lindau disease (VHL). Clin Genet. 2010 Jan;77(1):49 59. http://dx.doi.org/10.1111/j.1399-0004.2009.01281.x

8. Maher ER. Von Hippel-Lindau disease. Eur J Can. 1994 Jan;30(13):1987-90. http://dx.doi.org/10.1016/0959-8049(94) 00391-H

9. Zbar B, Kishida T, Chen F, Schmidt L, Maher ER, Richards FM, et al. Germline mutations in the Von Hippel-Lindau disease (VHL) gene in families from North America, Europe, and Japan. Hum Mutat. 1996;8(4):348-57. http://dx.doi.org/10.1002/(SICI)10981004(1996)8:4<348::AID-HUMU8>3.0.CO;2-3. PMID: 8956040.

10. Maher ER, Yates JR, Harries R, Benjamin C, Harris R, Moore AT, Ferguson-Smith MA. Clinical features and natural history of von Hippel-Lindau disease. Q J Med. 1990 Nov;77(283):1151-63. http://dx.doi.org/10.1093/qjmed/77.2. 1151. PMID: 2274658.

11. Lonser RR, Glenn GM, Walther M, Chew EY, Libutti SK, Linehan WM, Oldfield EH. von Hippel-Lindau disease. Lancet. 2003 Jun 14;361(9374):2059-67. http://dx.doi.org/10.1016/ S0140-6736(03)13643-4. PMID: 12814730.

12. Maher ER, Neumann HP, Richard S. von Hippel-Lindau disease: A clinical and scientific review. Eur J Hum Genet. 2011 Jun;19(6):617-23. http://dx.doi.org/10.1038/ejhg.2010.175

13. Blansfield JA, Choyke L, Morita SY, Choyke PL, Pingpank JF, Alexander HR, Seidel G, Shutack Y, Yuldasheva N, Eugeni M, Bartlett DL, Glenn GM, Middelton L, Linehan WM, Libutti SK. Clinical, genetic and radiographic analysis of 108 patients with von Hippel-Lindau disease (VHL) manifested by pancreatic neuroendocrine neoplasms (PNETs). Surgery. 2007 Dec;142(6):814-8; discussion 818.e1-2. http://dx.doi. org/10.1016/j.surg.2007.09.012. Erratum in: Surgery. 2008 Feb;143(2):302. PMID: 18063061; PMCID: PMC6771023.

14. Cassol C, Mete O. Endocrine manifestations of von HippelLindau disease. Arch Pathol Lab Med. 2015;139(2):263-8. http://dx.doi.org/10.5858/arpa.2013-0520-RS

15. Woodward ER, Maher ER. Von Hippel-Lindau disease and endocrine tumour susceptibility. Endocr Relat Cancer. 2006;13(2):415-25. http://dx.doi.org/10.1677/erc.1.00683

16. Zwolak A, Świrska J, Tywanek E, Dudzińska M, Tarach JS, Matyjaszek-Matuszek B. Pancreatic neuroendocrine tumours in patients with von Hippel-Lindau disease. Endokrynol Pol. 
2020;71(3):256-259. http://dx.doi.org/10.5603/EP.a2020.0027. PMID: 32797472.

17. Hes FJ, Höppener JWM, Lips CJM. Pheochromocytoma in Von Hippel-Lindau Disease. JClin Endocrinol Metab.2003;88(3):96974. http://dx.doi.org/10.1210/jc.2002-021466

18. Varshney N, Kebede AA, Owusu-Dapaah H, Lather J, Kaushik M, Bhullar JS. A review of Von Hippel-Lindau syndrome. J Kidney Cancer VHL. 2017 Aug 2;4(3):20-9. http://dx. doi.org/10.15586/jkcvhl.2017.88

19. Baghai M, Thompson GB, Young WF Jr, Grant CS, Michels VV, van Heerden JA. Pheochromocytomas and paragangliomas in von Hippel-Lindau disease: A role for laparoscopic and corticalsparing surgery. Arch Surg. 2002 Jun;137(6):682-8; discussion 688-9. http://dx.doi.org/10.1001/archsurg.137.6.682

20. Melmon KL, Rosen SW.Lindau's disease: Review of the literature and study of a large kindred. Am J Med.1964;36:595-617. https://doi.org/10.1016/0002-9343(64)90107-X

21. Tampieri D, Leblanc R, TerBrugge K, Rengachary SS, Berenstein A. Preoperative embolization of brain and spinal hemangioblastomas. Neurosurgery.1993;33(3):502-5. https:// doi.org/10.1227/00006123-199309000-00022

22. Bratslavsky G. Functional and oncologic outcomes of partial adrenalectomy for pheochromocytoma in patients with von Hippel-Lindau syndrome after at least 5 years of follow-up. J Urol. 2010 Nov;184(5):1855-9. http://dx.doi.org/10.1016/j. juro.2010.06.102

23. Walther MM, Reiter R, Keiser HR, Choyke PL, Venzon D, Hurley K, et al. Clinical and genetic characterization of pheochromocytoma in von Hippel-Lindau families: comparison with sporadic pheochromocytoma gives insight into natural history of pheochromocytoma. J Urol. 1999 Sep;162(3 Pt 1):659-64. http://dx.doi.org/10.1097/00005392-199909010-00004. PMID: 10458336.

24. Michels V, Van Heerden JA.Pheochromocytomas and paragangliomas in von Hippel-Lindau disease: A role for laparoscopic and cortical-sparing surgery. ArchSurg.2002;137(6):682-9. https://doi.org/10.1001/archsurg.137.6.682

25. Eisenhofer G, Walther MM, Huynh TT, Li ST, Bornstein SR, Vortmeyer A, et al. Pheochromocytomas in von Hippel-Lindau syndrome and multiple endocrine neoplasia type 2 display distinct biochemical and clinical phenotypes. J Clin Endocrinol Metab. 2001 May;86(5):1999-2008. http://dx.doi.org/10.1210/ jcem.86.5.7496. PMID: 11344198.

26. Chittiboina P, Lonser RR. Von Hippel-Lindau disease. Handb Clin Neurol. 2015;132:139-56. http://dx.doi.org/10.1016/ B978- 0-444-62702-5.00010-X

27. Young EE, Castle SM, Gorbatiy V, Leveillee RJ. Comparison of safety, renal function outcomes and efficacy of laparoscopic and percutaneous radio frequency ablation of renal masses. J Urol. 2012 Apr;187(4):1177-82. http://dx.doi.org/10.1016/j. juro.2011.11.099. Epub 2012 Feb 20. PMID: 22357170.

28. Charlesworth M, Verbeke CS, Falk GA, Walsh M, Smith AM, Morris-Stiff G. Pancreatic lesions in von Hippel-Lindau disease? A systematic review and meta-synthesis of the literature. J Gastrointest Surg. 2012 Jul;16(7):1422-8. http://dx.doi. org/10.1007/s11605-012-1847-0. Epub 2012 Feb 28. PMID: 22370733
29. Libutti SK, Choyke PL, Bartlett DL, Vargas H, Walther M, Lubensky I, et al. Pancreatic neuroendocrine tumors associated with von Hippel Lindau disease: diagnostic and management recommendations. Surgery. 1998 Dec;124(6):1153-9. http://dx. doi.org/10.1067/msy.1998.91823. PMID: 9854597.

30. Horton WA, Wong V, Eldridge R. Von Hippel-Lindau disease: Clinical and pathological manifestations in nine families with 50 affected members. Arch Intern Med. 1976;136(7):769-77. http:// dx.doi.org/10.1001/archinte.136.7.769

31. Tamura K, Nishimori I, Ito T, Yamasaki I, Igarashi H, Shuin T. Diagnosis and management of pancreatic neuroendocrine tumor in von Hippel-Lindau disease. World J Gastroenterol 2010 Sep 28;16(36):4515-8. http://dx.doi.org/10.3748/wjg.v16. i36.4515. PMID: 20857520; PMCID: PMC2945481.

32. Kos-Kudła B, Hubalewska-Dydejczyk A, Kuśnierz K, Lampe P, Marek B, Nasierowska-Guttmejer A, Nowakowska-Duława E, et al. Consensus Conference; olish Network of Neuroendocrine Tumours. Pancreatic neuroendocrine neoplasms - management guidelines (recommended by the Polish Network of Neuroendocrine Tumours). Endokrynol Pol. 2013;64(6):459-79. http://dx.doi.org/10.5603/EP.2013.0031. PMID: 24431118.

33. Hammel PR, Vilgrain V, Terris B, Penfornis A, Sauvanet A, Correas JM, et al. Pancreatic involvement in von Hippel-Lindau disease. The Groupe Francophone d'Etude de la Maladie de von Hippel-Lindau. Gastroenterology. 2000 Oct;119(4):1087-95. http://dx.doi.org/10.1053/gast.2000.18143. PMID: 11040195.

34. Benhammou JN, Boris RS, Pacak K, Pinto PA, Linehan WM, Bratslavsky G. Functional and oncologic outcomes of partial adrenalectomy for pheochromocytoma in patients with von Hippel-Lindau syndrome after at least 5 years of followup. J Urol. 2010 Nov;184(5):1855-9. http://dx.doi.org/10.1016/j. juro.2010.06.102

35. Weil RJ, Lonser RR, DeVroom HL, Wanebo JE, Oldfield EH. Surgical management of brainstemhemangioblastomas in patients with von Hippel-Lindau disease. J Neurosurg.2003;98(1):95-105. https://doi.org/10.3171/jns.2003.98.1.0095

36. Peng S, Zhang J, Tan X, Huang Y, Xu J, Silk N, et al. The VHL/HIF Axis in the Development and Treatment of Pheochromocytoma/Paraganglioma. Front Endocrinol (Lausanne). 2020 Nov 24;11:586857. http://dx.doi.org/10.3389/ fendo.2020.586857. PMID: 33329393; PMCID: PMC7732471.

37. Maharjan CK, Ear PH, Tran CG, Howe JR, Chandrasekharan C, Quelle DE. Pancreatic neuroendocrine tumors: Molecular mechanisms and therapeutic targets. Cancers (Basel). 2021;13(20):5117. http://dx.doi.org/10.3390/cancers13205117

38. Flores SK, Estrada-Zuniga CM, Thallapureddy K, ArmaizPeña G, Dahia PLM. Insights into mechanisms of pheochromocytomas and paragangliomas driven by known or new genetic drivers. Cancers (Basel). 2021;13(18):4602. http://dx.doi. org/10.3390/cancers 13184602

39. Tung I, Sahu A. Immune checkpoint inhibitor in first-line treatment of metastatic renal cell carcinoma: A review of current evidence and future directions. Front Oncol. 2021;11:707214. http://dx.doi.org/10.3389/fonc.2021.707214 